\title{
DESDE EL IDEAL DE LA INTEGRACIÓN LATINOAMERICANA A REPENSAR LA INTEGRACIÓN REGIONAL
}

Las transformaciones fundamentalmente políticas, pero también sociales y económicas evidenciadas a nivel global desde fines del siglo pasado y comienzos del actual, han repercutido en mayor o menor medida en las estructuras gubernamentales de los Estados en general y de la región latinoamericana en particular. En tal sentido, a raíz de los cambios en las orientaciones políticas, se han registrado modificaciones en la asignación de los recursos de origen fiscal con una fuerte inclinación hacia nuevas formas de administración y gestión en busca de procurar la satisfacción de necesidades que emergen de la dimensión social.

Paralelamente, la adopción de los Objetivos del Desarrollo Sostenible de las Naciones Unidas para el año 2030 (ODS 2030) ha colaborado como disparador en la reformulación de las diferentes políticas públicas en pos de alcanzar el mayor grado de satisfacción posible en cuanto al cumplimiento de los mismos -los objetivos-, entendiendo que a partir de la conformación de estructuras fiscales fuertes es posible generar nuevas instancias de concertación, cooperación e integración.

Este nuevo paradigma de gestión gubernamental mostrado en los últimos años sumado a la incertidumbre y el futuro incierto de los distintos esquemas de integración en Latinoamérica, obliga a un replanteo de las materias y los sectores que resultan prioritarios para el desarrollo de acciones conjuntas de los países integrados.

El contexto descripto ha sido receptado por los estudios que conforman este nuevo número de "Aportes para la Integración Latinoamericana".

En tal sentido, en la Sección Tema Central se publica el trabajo realizado por la Dra. Ana Lía del Valle Guerrero de la Universidad Nacional del Sur titulado Repensar la integración energética sudamericana frente a la incertidumbre de la integración regional y la transición energética global. En el mismo se analiza desde una mirada multiescalar y multidimensional - es decir no solo desde un punto de vista político- el proceso de la integración energética en la Región Sudamericana y el futuro posible de la misma a partir de los cambios registrados en los distintos procesos de integración y tomando en consideración la transición energética mostrada a escala global.

En la Sección Estudios se incluye el trabajo denominado Proyecto de confederación latinoamericana de 1862. Un ignorado precursor boliviano de la teoría de la integración 
regional, cuya autoría pertenece al Dr. Germán A. de la Reza de la Universidad Autónoma Metropolitana de México. En el mismo se pone de relieve a través del análisis de documentos históricos atribuidos al escritor potosino Benedicto Medinaceli, la incipiente idea y concepción de un proyecto de integración latinoamericana -el mismo data del año 1862- que fuera utilizada como plataforma para el establecimiento de un sistema de sustitución de importaciones y de protección y fomento de una industria incipiente entre otras medidas.

El trabajo incorporado a la Sección Opinión titulado Sector Agroalimentario e Integración Regional: una simbiosis necesaria para la seguridad alimentaria y nutricional del Mag. Oscar E. Fernández-Guillen de la Universidad de los Andes (ULA, Mérida, Venezuela), efectúa un análisis de la relación que existe entre los procesos de integración, la agricultura y la seguridad alimentaria en América Latina, tratando de demostrar que de la conjugación de estos tres elementos surge la posibilidad de crear un instrumento capaz de suministrar alimentos de manera fluida y con costos transaccionales beneficiosos aun ante turbulencias en los mercados internacionales.

Asimismo, los Documentos que integran este número son los que se detallan a continuación:

\section{ALIANZA BOLIVARIANA PARA LOS PUEBLOS DE NUESTRA AMERICA- TRATADO DE COMERCIO DE LOS PUEBLOS -ALBA-TCP-}

XVII Cumbre de Jefes de Estado y de Gobierno del ALBA-TCP. Declaración de La Habana, 14 de diciembre de 2019

\section{COMUNIDAD ANDINA DE NACIONES -CAN-}

Declaración de los Ministros de Relaciones Exteriores y de Comercio Exterior de la Comunidad Andina respecto a la propagación del Coronavirus (COVID-19) Presidencia Pro-Tempore de Bolivia. 8 de abril de 2020.

\section{- COMUNIDAD DEL CARIBE -CARICOM-}

Declaración Conjunta de la Organización de Estados Africanos, del Caribe y del Pacifico, la Comunidad del Caribe y la Secretaria del Foro de las Islas del Pacifico sobre la Pandemia COVID-19. 18 de mayo de 2020. 


\section{- $\quad$ MERCADO COMUN DEL SUR -MERCOSUR-}

Comunicado conjunto de los Presidentes de los Estados Partes del MERCOSUR y Estados Asociados, en ocasión de la LV Cumbre de Presidentes. República del Brasil, Ciudad de Bento Goncalves, 5 de Diciembre de 2019.

\section{- $\quad$ MERCADO COMUN DEL SUR -MERCOSUR-}

Declaración de los Presidentes de los Estados Partes del MERCOSUR y Estados Asociados sobre Desarrollo Sostenible, en ocasión de la LV Cumbre de Presidentes. República del Brasil, Ciudad de Bento Goncalves, 5 de Diciembre de 2019.

\section{- $\quad$ SISTEMA DE INTEGRACION CENTROAMERICANO -SICA-}

Declaración de los Jefes de Estado y de Gobierno de Belize, Costa Rica, Guatemala, Honduras, Nicaragua, Panamá y República Dominicana ante la Pandemia del COVID19. Presidencia Pro-Tempore de Honduras. 12 de marzo de 2020. 